\title{
\begin{tabular}{|ll} 
JCAU \\
J
\end{tabular}
}

\section{A Look at the Architectural Cultural Exchange Between East and West During the Yuan and Ming Dynasties from the Brick- Vaulted Bathroom Outside Nanjing's Zhonghua Gate - A Secondary Publication}

\author{
Ying Bai ${ }^{1}$, Tao Chen ${ }^{2}$ \\ ${ }^{1}$ School of Architecture, Southeast University, Nanjing, Jiangsu, China \\ ${ }^{2}$ National Defense Engineering College, Army Engineering University, Nanjing, Jiangsu, China
}

Corresponding author: Ying Bai, School of Architecture, Southeast University, Nanjing, Jiangsu, China. Email: baiying@seu.edu.cn

Citation: Bai Y, Chen T, 2021, A Look at the Architectural Cultural Exchange Between East and West During the Yuan and Ming Dynasties from the Brick-Vaulted Bathroom Outside Nanjing's Zhonghua Gate - A Secondary Publication. Journal of Chinese Architecture and Urbanism, 3(2): 1167. http://dx.doi.org/10.36922/jcau.v3i2.1167

\begin{abstract}
There is a brick-vault roofed bathroom building, commonly known as the Cistern Hall (Wengtang), opposite the Grand Baoen Temple Heritage and Scenic Area near the Zhonghua Gate in Nanjing. This article analyzes its shape and characteristics by means of a 3D scan that surveys and maps out 2019 data on the site. On this basis, this article suggests that the bathroom may have been built as an annex to the Grand Baoen Temple in the early Ming dynasty. This kind of bathroom design originated in West Asia, entered China during the Yuan dynasty (1271-1368) and became popular in the Jiangnan region during the Ming (1368-1644) and Qing (1644-1911) dynasties. In a lively exchange of architectural ideas, it bore witness to rich, in-depth architectural cultural exchanges between China, Central Asia, and West Asia in the Yuan and Ming dynasties.
\end{abstract}

Keywords: Cistern Hall (Wengtang), Yude Hall, domed roof, public bath, architectural cultural exchange, Yuan and Ming architecture

This article belongs to Secondary Publication Section, and is translated by Douglas Ellsworth from an article published in Journal of Architecture History 《建筑史学刊》. Citation of primary version: Ying Bai, Tao Chen, 2021, The Domed Bathhouse Near Zhonghua Gate of Nanjing and the Architectural Exchange between East and West Asia in the 13th and 14th Centuries. Journal of Architecture History, 2(1): 145-157. http://dx.doi.org/ http://dx.doi.org/10.12329/20969368.2021.01013

Copyright: @ 2021 Journal of Architecture History. This is an open-access article distributed under the terms of the Attribution-Non-Commercial 4.0 International 4.0 (CC BY-NC 4.0), which permits all non-commercial use, distribution, and reproduction in any medium provided the original work is properly cited. 


\section{INTRODUCTION}

The Silk Roads brought about an exchange of architectural culture between the East and the West. In the history of Chinese architecture, several major developmental transitions and morphological changes relate closely to the rise and fall of China's Western Regions and the Silk Roads ${ }^{[1]}$. Cultural exchanges between the East and the West thrived during the Yuan dynasty (1271-1368). A large number of immigrants from western and central Asia entered China, bringing new religions and cultures, giving rise to an impact on architecture in both the Yuan and Ming (1368-1644) dynasties. Despite the abundance of research on this topic, earlier research focused primarily on religious architecture. Architectural and cultural exchanges then were widespread, as they were in regard to religious buildings, palace buildings, residential buildings, and so forth. This article focuses on public bathrooms in residential buildings. It does not focus on Chinese architectural history, but rather, on public restrooms used in the Yuan and Ming dynasties as evidence of China's external architectural cultural exchanges.

The unique public bathroom outside the Zhonghua Gate in Nanjing commonly known as the Cistern Hall (Wengtang), built during the Ming dynasty, is now a cultural relics protection unit in Jiangsu Province. The main structure of the bathroom is a brick-vaulted roof, completely different from traditional Chinese wooden buildings. This article analyzes its formal characteristics, style and technological origins by means of this investigation.

\section{FORMAL CHARACTERISTICS AND HISTORICAL RESEARCH}

\subsection{Overview of bathroom structure}

The Cistern Hall (Wengtang) is located on Yuelai Lane, southwest of Zhonghua Gate in Qinhuai District, Nanjing City, Jiangsu Province. Jubao Gate was the gate south of the Zhonghua Gate in Nanjing during the Ming Dynasty. The Grand Baoen Temple was situated east of the Jubao Gate, with a longhistoric commercial market along the west side. West Street runs southwest to northeast through this area. The Yudai River winds along West Street and flows into the Qinhuai River at a point where vendors gathered at that time. Yuelai Alley was one of many alleys east of West Street leading to the main street outside Zhonghua Gate. Renovation of the area along West Street began in 2014, and major changes have been made to the environs of the Cistern Hall (Wengtang), which was no longer being used as a bathroom as of 2013, although the building is currently kept intact [Figure 1].

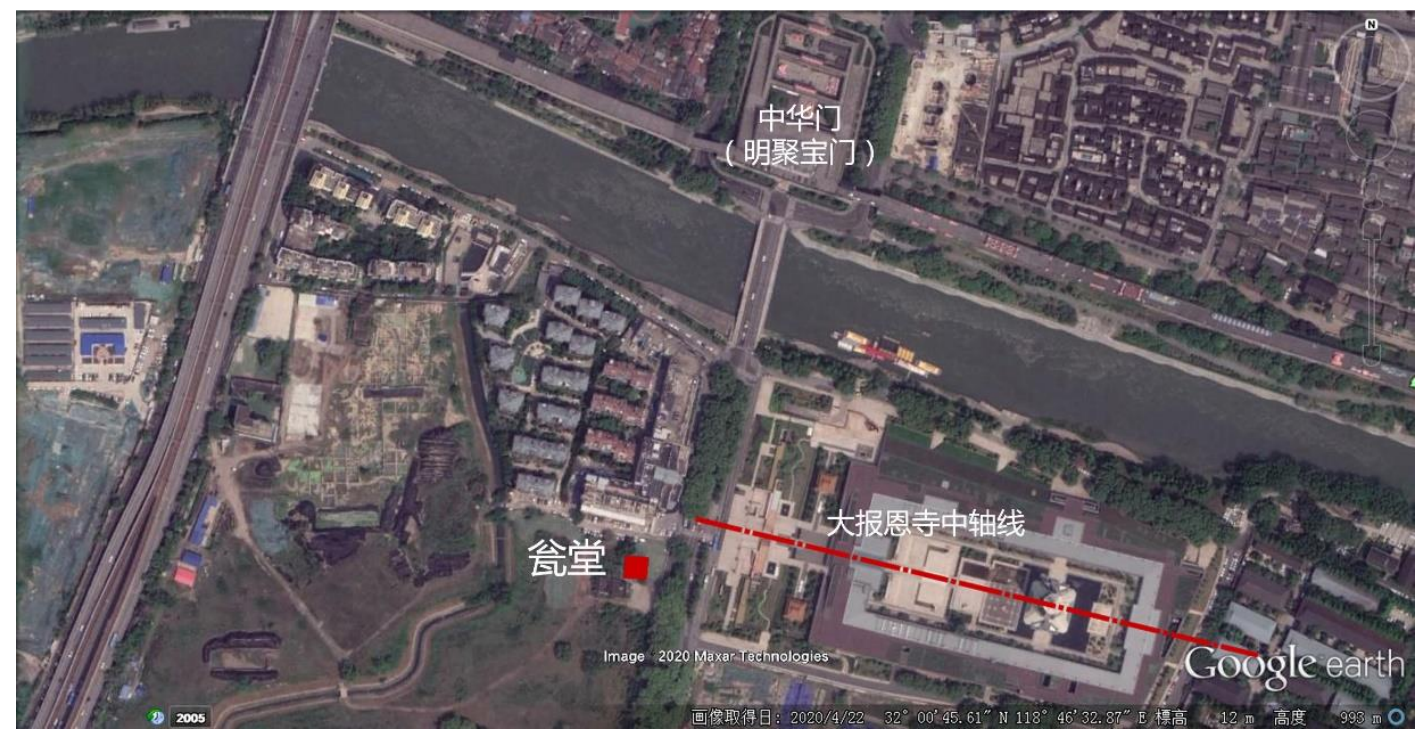

Figure 1. Cistern location map. 大报恩寺中轴线, central axis of Grand Baoen Temple; 瓮堂, Cistern Hall (Wengtang); 中华门（明聚宝门）, Zhonghua Gate (Ming Jubao Gate). Source: Google Earth 
Onsite surveys and 3D map scanning were conducted on the Cistern Hall (Wengtang) in May 2019. First, based on an onsite survey and mapping, an analysis of its layout and structural characteristics was made.

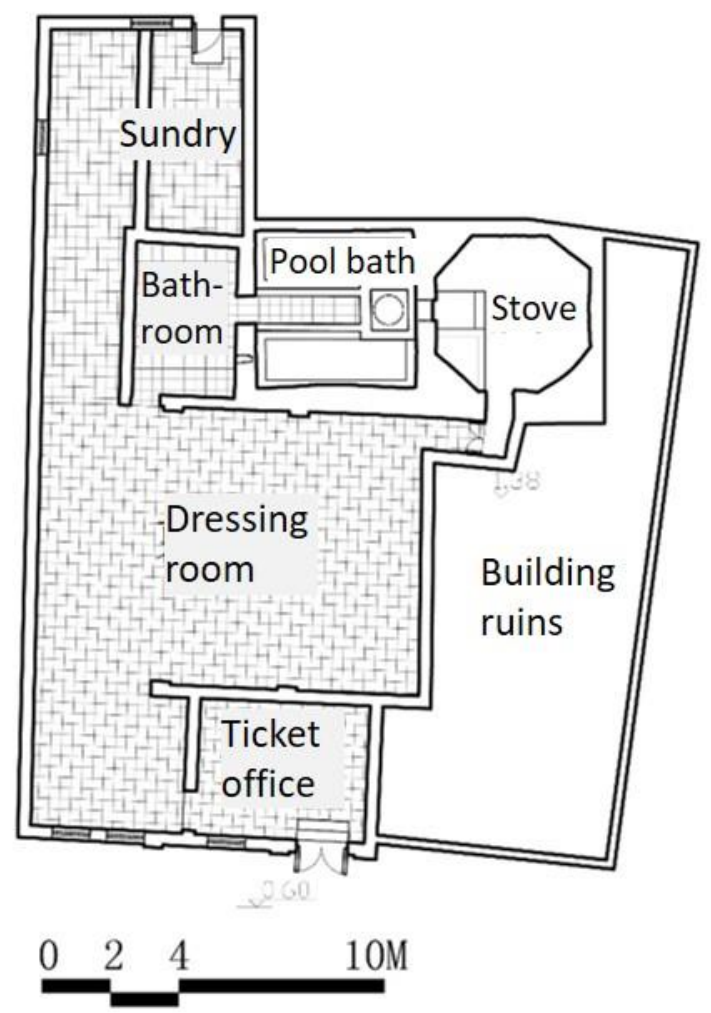

The Cistern Hall (Wengtang) is located north of Yuelai Lane and serves as the main entrance to the hall. The entrance is the bathroom foyer, behind which is the main bathroom, consisting of an area for changing clothes on the south side and one for bathing on the northside [Figure 2].

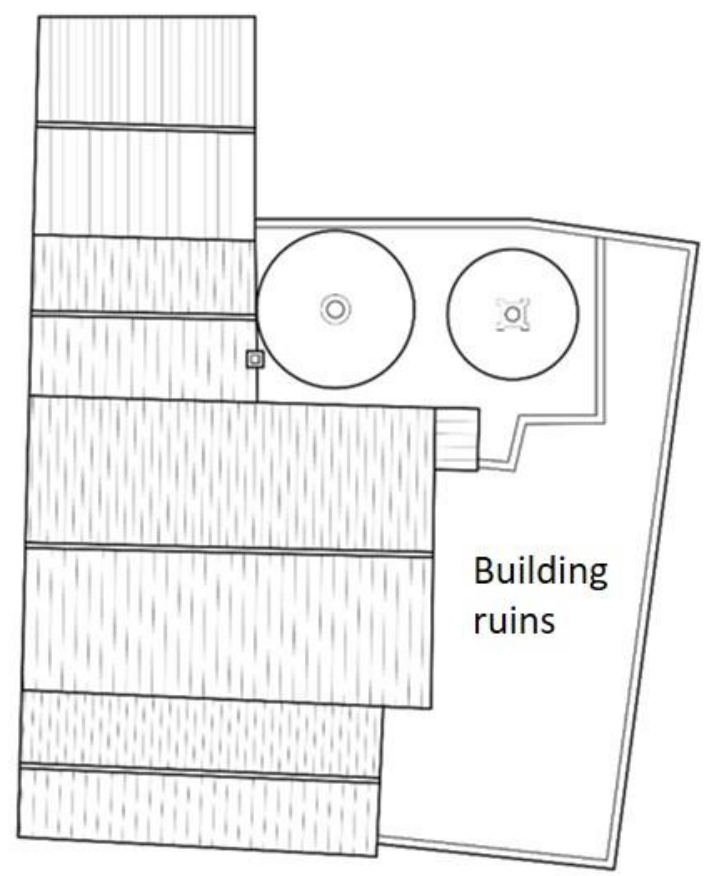

Figure 2. Cistern general plans. Source: Drawing by the authors

The dressing room was $91.5 \mathrm{sqm}$ in size. In addition to bathing, reclining chairs and closets allowed for leisure activities, an important aspect of the traditional bathroom. The load-bearing dressing room had brick columns, and the suspended ceiling was double-pitched and supported by a triangular wooden roof truss. The bathing area was rather complex, with a number of spaces that included a shower area, restroom, and stove space arranged from west to east on the north side of the dressing room [Figures 3 and 4].

Access to the shower room could be gained from the northwest of the locker room, the shower room plan is a rectangle shape longer in the north-south orientation. The faucets were arranged along one wall. Hot water was supplied by a water heater from the outside. The double-sloped roof structure above the arched ceiling was composed of a triangular wooden truss.

There was an archway on the east wall of the shower room, with a door measuring 1.61 $\mathrm{m}$ high and $0.8 \mathrm{~m}$ wide, and an arched niche of $0.2 \mathrm{~m}$ high on the left and right sides of the entranceway. The pool and bathroom were square-shaped; with the middle passage acting as a boundary. There were two baths in the north and south areas. The two baths were of equal size, each was $4.12 \mathrm{~m}$ long, $1.2 \mathrm{~m}$ wide, $0.38 \mathrm{~m}$ deep, and the edge was $0.24 \mathrm{~m}$ wide along the side of the walkway. There was an outer edge that was $0.3 \mathrm{~m}$ higher than the inner edge. At the east end of the walkway was a $0.72 \mathrm{~m}$ diameter iron pot right next to 
the bath, to which heated water could be added via an outlet on the wall next to the pot. The brick-structured pool and bathroom had a circular domed top with a round window set in the dome. There was a curved white-tiled vertical wall on the lower part of the inner surface covered in white plaster.
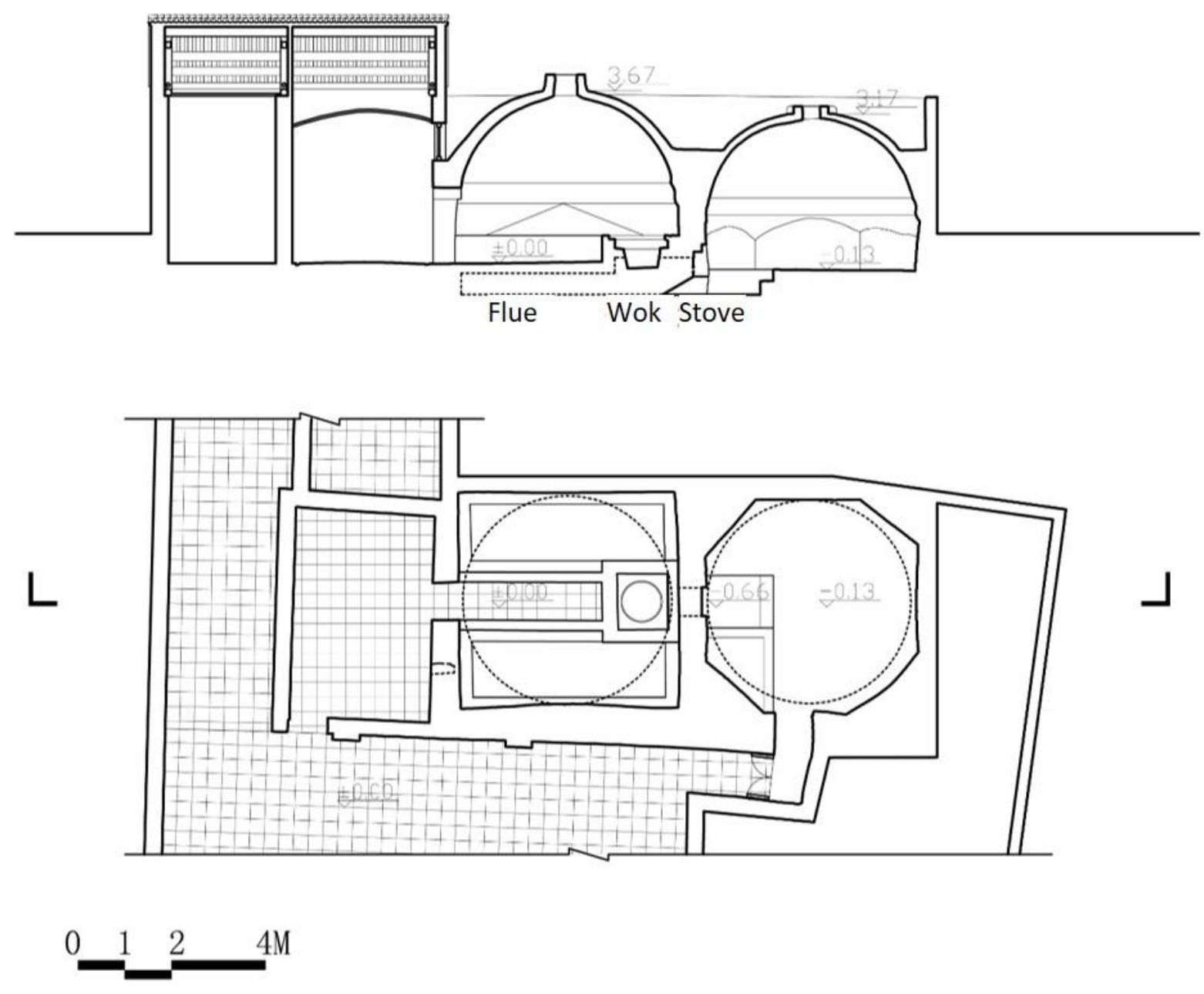

Figure 3. Plan and section of the cistern bathing area. Source: Drawing by the authors

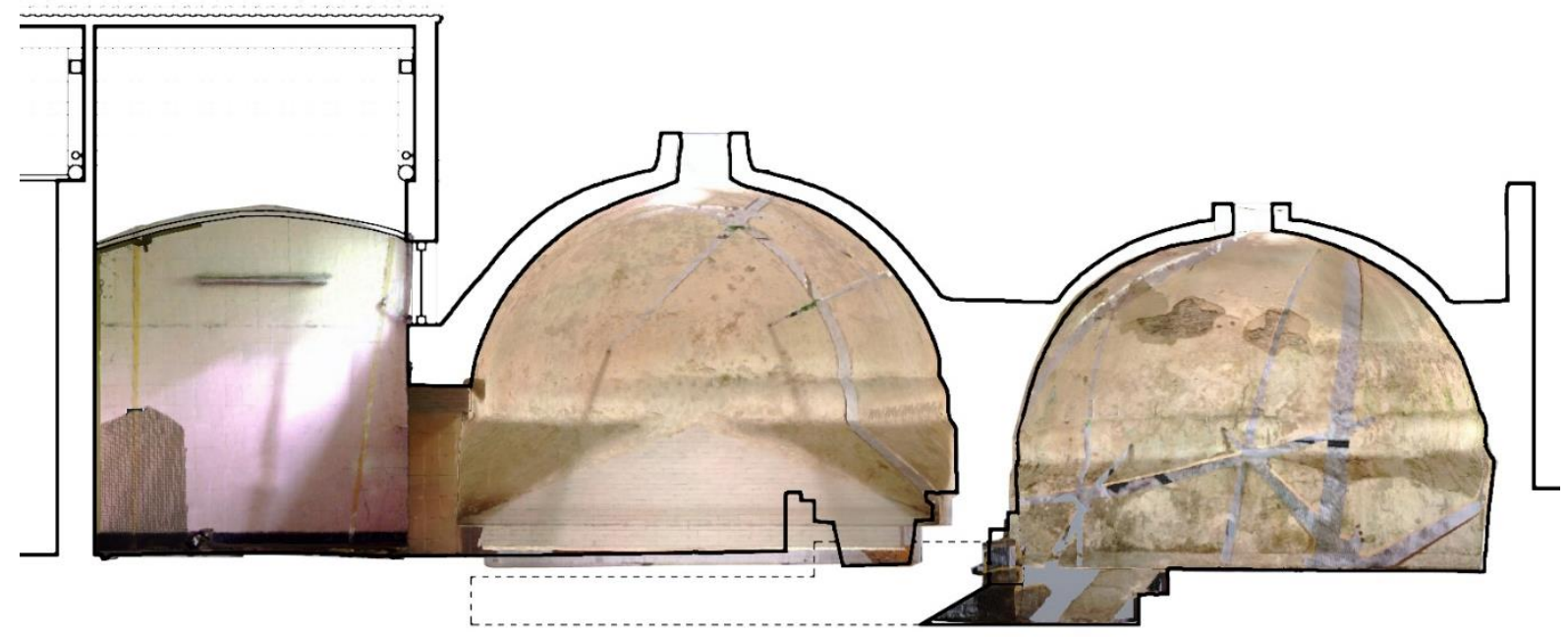

Figure 4. 3D scanned view of the cistern bathing area. Source: Drawing by the authors 
The octagonal stove room was behind the wall east of the iron pot. The stove was located at the juncture with the bathroom in the lower part of the wall. The $0.56 \mathrm{~m}$ wide stove mouth faced east, with the ground elevation of the stove mouth $0.52 \mathrm{~m}$ lower. The entrance to the stove room was the eastwest aisle between the dressing room and the bathing area south of the octagon. The brick stove room had a circular domed roof, with one round opened window at the top, its inner surface plastered white. The water pipe added later was installed via a window opening above the stove, extending through the wall to the iron pot in the bathroom [Figure 5].
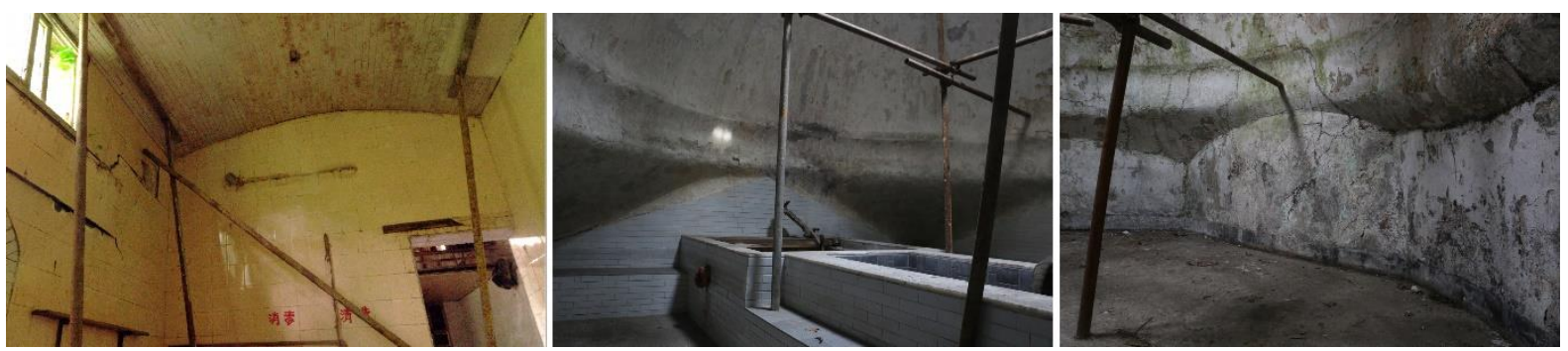

Figure 5. Interior of the cistern shower, pool bath, and stove room. Source: Photo by the authors

Moreover, it is worth noting that a chimney rose from the ground to above the roof along the partition wall between the shower room and the bathroom. Judging from the relative position of the stove and chimney, as well as the height difference between the stove mouth and the indoor floor of the bathroom, there was likely a flue in the ground between the stove and the chimney, which was used to provide heat to the bathroom floor.

A row of relatively small rectangular spaces stood west and north of the bathing area. The roof was composed of two consecutive double-slope tops (the interior, east section of the south-slope top was the shower room). The south-side slope-top was a triangular roof truss structure, while the north-side roof was a traditional wooden roof truss. Therefore, although blocked off, it may have existed previously and was used as an auxiliary entrance.

The east side vault functioned as a stove before being shuttered, but studies suggest that the two vault spaces were once used by different people for bathing ${ }^{[2]}$. Conclusions cannot currently be drawn; in addition, the water supply and drainage method has been changed, and the onsite environment has changed a lot, so the original water supply and drainage facilities of the bathroom cannot be determined now.

\subsection{An analysis of the vault characteristics}

The bathing area and stove room were the earliest, most distinctive parts of the bathroom. The following is a further analysis of the structure of the two vaults based on the surveys and mapping data.

The west dome was a square plan that was to become round, the bottom was about $4.6 \mathrm{~m}$ long, with slight deformities in the south-side wall. The square-shaped west dome also turned into a circle.

The dome stretched from an octagon, the eight sides of which were not exactly the same. The general rule was that the four orthogonal sides were relatively longer, 2.23$2.33 \mathrm{~m}$, and the four corners were relatively shorter, $1.48-1.64 \mathrm{~m}$, which is a large distortion of the southeast hypotenuse. The vertical distance between both sides is $4.5 \mathrm{~m}$ orthogonally.

The wall thickness of the two domes is $0.5 \mathrm{~m}$, and the upper dome was basically on the inscribed tangent of the lower plan.

The total height of the vault space in the pool and bathroom was $3.53 \mathrm{~m}$. According to the form and design, the two brick-vault structures could be divided into three parts from bottom to top: the vertical wall, the transition layer, and the vault. The vertical wall was not overly high. The lowest point of the transition layer was only $0.42 \mathrm{~m}$, and the 
highest point in the middle of each side was $1.27 \mathrm{~m}$, barely able to accommodate one person sitting beside the bath. This part of the conversion layer mainly played the role of transitioning from the square-plan vertical wall to the upper round roof, and the corners were protruding triangles. The outline of the triangle was an arc in the plan with a cloudlike appearance, and the cross section was close to an oblique straight line. It is presumed to have been layered. The horizontal direction was constructed layerby-layer according to the arc, and the vertical direction was also evenly formed layer-bylayer [Figure 6]. The upper part of the triangle formed a circular base with a height of 0.42 $\mathrm{m}$. The diameter was slightly retracted from the bottom to the top, and the dome rose from this circular base. The dome above the base was composed of two double-center arcs that comprised less than $1 / 4$ of a circle.

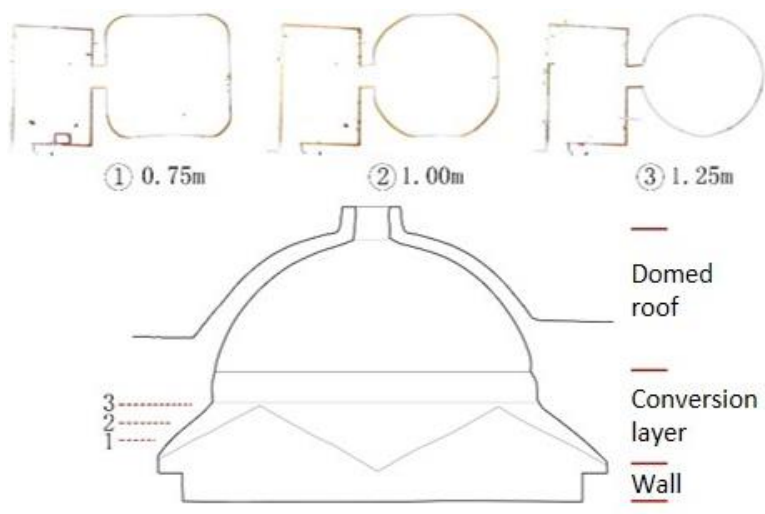

Figure 6. Plan-point cloud slices and 45-degree crosssection of the vault conversion layer in the cistern bathroom pool. Source: Drawing by the authors

The stove room was lower, and the center of the vault was $3.19 \mathrm{~m}$ above the ground. The vertical wall was $0.62-0.82 \mathrm{~m}$ high. The conversion layer transition from octagon to circle also used an overhanging triangle, but the overhanging distance of the octagonal corner was much smaller than that of the bathroom. The upper part also had a slightly retracted circular base, and the base was a double-centered dome.

The thickness of the arch varied. It generally was relatively thinner near the top and thicker at the bottom.
The appearance of the two vault structures was relatively simple. As part of the group, they were hidden in adjacent buildings and surrounding blocks, and had no independent facades. The only feature that could be discerned was the roof. Two hemispherical bulges with openings at the top were raised above the flat roof in a certain slope, and the outer surface was covered with the same mortar as the flat roof [Figure 7].

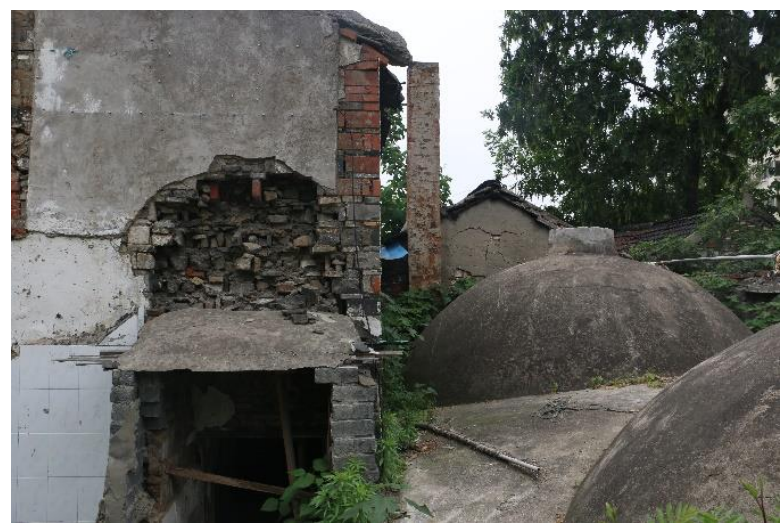

Figure 7. Photograph of the cistern roof bathing area. Source: Photo by the authors

Due to limitations in this investigation and changes at the site, some issues cannot be accurately determined. For example, the inner and outer surfaces of the vault are plastered, so the vault construction methods cannot be determined. From the damaged part of the plastering on the vault surface of the stove, it can be seen that the vault was made using blue bricks about $2 \mathrm{~cm}$ thick horizontally, and the gaps between the bricks were white mortar bonding.

\subsection{Research on the history of the Grand Baoen Temple Gate}

Folklore claims that the Cistern Hall (Wengtang) was constructed as a bathroom in the early Ming dynasty for the work crew that built the Nanjing City Wall to bathe. Based on the Jinling Pure Land Chronicles (Jinling Fan Cha Zhi), Zheng Zihai pointed out that the Cistern Hall (Wengtang) belonged to the Grand Baoen Temple during the Ming dynasty, speculating that it was built for the use of supervising officials and monks as a place to bathe ${ }^{[2]}$. 
Table 1. Data sheet of vault between bathroom and stove

\begin{tabular}{|c|c|c|c|c|c|c|c|c|c|c|}
\hline \multirow[t]{2}{*}{ Project } & \multicolumn{3}{|c|}{ Wall } & \multicolumn{3}{|c|}{$\begin{array}{l}\text { Conversion layer } \\
\end{array}$} & \multicolumn{4}{|c|}{ Vault plane shape } \\
\hline & $\begin{array}{l}\text { Plane } \\
\text { shape }\end{array}$ & $\begin{array}{l}\text { Side } \\
\text { length }\end{array}$ & Height & $\begin{array}{l}\text { Height of } \\
\text { triangle }\end{array}$ & $\begin{array}{l}\text { Height of } \\
\text { circular } \\
\text { base }\end{array}$ & $\begin{array}{l}\text { Diameter } \\
\text { of circular } \\
\text { base }\end{array}$ & $\begin{array}{l}\text { Plane } \\
\text { diameter }\end{array}$ & Height & $\begin{array}{l}\text { Height- } \\
\text { span ratio }\end{array}$ & $\begin{array}{l}\text { Top hole } \\
\text { inner } \\
\text { diameter }\end{array}$ \\
\hline $\begin{array}{l}\text { West } \\
\text { Dome }\end{array}$ & Square & 4.6 & 0.42 & 0.93 & 0.42 & 4.6 & 4.45 & 1.85 & 0.42 & 0.5 \\
\hline $\begin{array}{l}\text { East } \\
\text { Dome } \\
\end{array}$ & $\begin{array}{l}\text { Eight } \\
\text { sides }\end{array}$ & $2.28 / 1.55$ & $\begin{array}{l}0.62- \\
0.82 \\
\end{array}$ & $0.38-0.55$ & 0.42 & 4.55 & 4.33 & 1.71 & 0.39 & 0.38 \\
\hline
\end{tabular}

Unit: meter

The Grand Baoen Temple was located on the east side of Jubaomenwai Street. It was built by the Ming-dynasty Yongle Emperor Chengzu (personal name Zhu Di) on the site of the original Song-dynasty Tianxi Temple to honor his parents' kindness to him. The construction began in Yongle's 10th year (1412) and continued into the reign of the Xuande Emperor (personal name Zhu Zhanji), during which it was completed, after which it became one of the Ming's highest-level temples in Nanjing. As a result of the terrain upon which it was erected, the Grand Baoen Temple was situated in the east while facing west. According to the records of the Jinling Pure Land Chronicles (Jinling Fan Cha Zhi) during the reign of the Ming dynasty Wanli Emperor (personal name: Zhu Yijun), there was a bathing hall in front of the Grand Baoen Temple, belonging to the temple, as was the case with the Tiandi Tangdang Temple ${ }^{[3]}$. The temple rented out for 22 taels of silver per year, but for the monks to bathe there it cost seven taels [3]. The Wary Pure Land Chronicles (Zhe Yi Fan Sha Zhi), compiled during the reign of the Jiaqing Emperor (personal name Yongyan) of the Qing dynasty, notes that "the bathhouse in front of the Grand Baoen Temple rents for 28.57 taels of silver per year" [4]. The Cistern Hall (Wengtang) is located just across the street from the Grand Baoen Temple gate, which is consistent with the location of the "Temple Front Bathing Hall" in the literature. Consequently, the article also indicates that the cistern is the "Temple Front
Bathing Hall" of the great Grand Baoen Temple mentioned in Ming and Qing literature. Monks could bathe there, and it was also leased to ordinary people for bathing.

The Jinling Pure Land Chronicles (Jinling Fan Cha Zhi) was compiled in the 35th year of Wanli (1607), and the cistern should be about this old. However, the brick bathroom attached to the Buddhist temple in Nanjing in fact appeared during the Ming reign of the Hongwu Emperor (personal name Zhu Yuanzhang) at the latest. In the 21st year of the Hongwu Emperor (1388), Tianjie Temple (the original Longxiang Jiqing Temple), one of the three major temples in Jinling (an older name for Nanjing), along with the Grand Baoen Temple, moved from the city to outside the Jubao Gate (also known as the Gate of China) in Jinling. The temple was built with corridors and rooms for rent in a manner dating from previous times in order to benefit the temple. ${ }^{1} \mathrm{~A}$ "Mixed Hall" was a common term for a brick bathroom in the Ming and Qing dynasties. Therefore, it can be inferred that setting up bathing halls for renting operations near temples may have been a relatively normal act at large temples in Nanjing in the early Ming dynasty.

Historical records state that, after the completion of the Grand Baoen Temple in the 3rd year of Xuande (1428), the wood factory site that was located on the west side of the temple under the Yuewang Terrace was left unused and was given to the temple to grow vegetables ${ }^{[2]}$. Accordingly, the site of the Cistern Hall (Wengtang) bathroom near

\footnotetext{
${ }^{1}$ [The 21st Year of Hongwu (1388)] "In the early dynasty on June 15th, according to imperial decree, the original corridor and Mixed Hall of the elders of the Shanshi Zen Temple were assembled as previously done, asking for house money, and admired.” See Ge Yinliang's Jinling Pure Land Chronicles, page 224.
} 
Yuewang Terrace is also likely to have belonged to the Grand Baoen Temple at this time. Therefore, the original construction of the Cistern Hall (Wengtang) was likely to have coincided with the construction of the Grand Baoen Temple. The brick structure of the existing Cistern Hall (Wengtang) bathroom should date back to the early Ming dynasty.

\section{PUBLIC BATHS IN ANCIENT CHINA}

Ancient Chinese public baths had a close relationship with Buddhism. Eastern Han dynasty An Shigao's translation of Buddha Says the Greenhouse Bathing Monks Sutra (Fo Shuo Wen Shi Xi Yu Zhong Seng Jing) states that bathing can help one avoid unpleasantries and obtain blessings. Thus, after Buddhism became popular in China, many Buddhist temples were built with bathrooms for monks to bathe in. During the post-Liang period, the monk Zhihui built a bathroom in a capital temple and opened it to the public every 5th day, "on the day of opening, the crown princes and gentlemen gather." ${ }^{[5]}$ The prevalence of public baths in the Song dynasty (960-1279) was probably influenced by the public baths of Buddhist monasteries.

Most of the bathrooms before the Ming dynasty no longer exist, but from the "Five Mountains and Ten Temples" (Wu Shan Shi Sha $T u$ ) painted by Japanese monks in the Southern Song dynasty (1127-1279), one can roughly understand the basic conditions of bathrooms during that time [Figure 8]. During the Southern Song dynasty, Zen Buddhism formed a unique regulation in their monasteries. In the layout of the sangharāma (a Buddhist monastery with a garden or grove), the bathing area was requisite for each temple, with a toilet symmetrically placed on both sides. Song-dynasty Japanese monks who visited the Five Mountains and Ten Temples (a series of state-sponsored Zen Buddhist temples) south of the Yangtze River mapped the architectural system and introduced it to Japan, which included an image of the Tiantong Temple in Ningbo. Xuanming was the bathroom in the Zen temple, also known as the "Perfume Sea." According to Zhang Shiqing's research, the bathroom depicted in the Xuanming picture of Tiantong Temple is a building with seven-bay wide and four-bay deep, with two kitchen buildings at the back. It is resolutely proclaimed to be the Zen temple bathroom known as the Perfume Sea. Zhang Shiqing, a professor of architecture at Southeast University in Nanjing, stated that the bathing area was seven-room wide and four-room deep in size, with two kitchens in the back ${ }^{[6]}$. The baths were located in a room beneath overhanging eaves in the rear of the building. Two square pools, with a screen between each of them, connected end-to-end horizontally within the middle of the building. Seating and round bathtubs were situated along both sides of each pool. There was also a railing stretching around the outside and a blocking screen placed in the center. An image of a monk resembling an incense burner was at the front of the bathing area with candlesticks and hand-washing buckets to either side and a hearth to dry foot coverings. A wok attached to a square stove to boil water can be seen near the back wall of the bathing area with a small hole between the wok and the bath for hot water to flow through.

The Tiantong temple appears to have been made of wood, judging by the columns in the picture ${ }^{[5,7]} .{ }^{2}$ The indoor area was relatively large to accommodate the bathing monks, with the dressing and bathing areas

\footnotetext{
2 The private bathroom in and before the Southern Song Dynasty was also a wooden structure. The architectural ruins of the begonia soup and the lotus soup found in the archaeological section I of the Huaqing Palace in Tangli Mountain all have column foundations, indicating that the bathroom of the Huaqing Palace was a wooden structure. Refer to the Western Shaanxi Provincial Cultural Relics Administration Tang Huaqing Palace, pages 253, 262. According to Yang Zhishui's research, the bathroom described in Shu Yuexiang's New Bath in Spring in the Southern Song Dynasty was a slab house with small windows on the wall; see Yang Zhishui's "Orchid Soup and Perfume."
} 
sharing the same space. Only the stove had a separate area. The bathing area was separated from other sections by railings and screens, with the poolside screens serving as a type of barrier. With partitions in the room, the Tiantong Temple's bathroom was in line with the traditional Chinese wooden structures. However, as a bathroom, there were a number of shortcomings with this architectural form. First, the thermal insulation in such a large area is rather inadequate in wooden structures, so it was difficult to maintain the indoor temperature during bathing. Second, wooden structures are prone to decay in a wet environment. Third, heat needs to be maintained during the bathing process, so the fireproof performance of wooden structures was also a challenge. The Bai Zhang Qing Regulations (Bai Zhang Qing Gui) stipulates that after bathing, the monks must "dampen the fire and observe it carefully in the stove, and sprinkle water on the charcoal while keeping firewood at a safe distance" ${ }^{[8]}$ to prevent fires.
Chinese public bathrooms began to change with the appearance of bricks during the Yuan dynasty so that a bathing area became referred to as a "Mixed Hall" in the literature. Xie Zongke of the Yuan dynasty apparently had a poem titled "Mixed Hall": "The fragrant warm spring gushes out the pond. It is difficult to wash off the dust of the world. The chaotic shell is still dim and the night is as warm as spring." The last two lines of the poem describe a Mixed Hall. The feature was a shell-like bathroom space, and the interior was warm like spring. Liu $\mathrm{Yu}$ of the Yuan dynasty made a record of this in the 6th year (1319) of the Yanyou period (13141320) and traveled west to the city of Changde in Hunan Province. After crossing the Syr Darya River in Central Asia, he noted the resemblance of local brick-built post pavilions and guest houses there to bathing spaces. According to Liu Yu's understanding of Changde, the bathroom was most likely a brick building ${ }^{[9]} 3$.

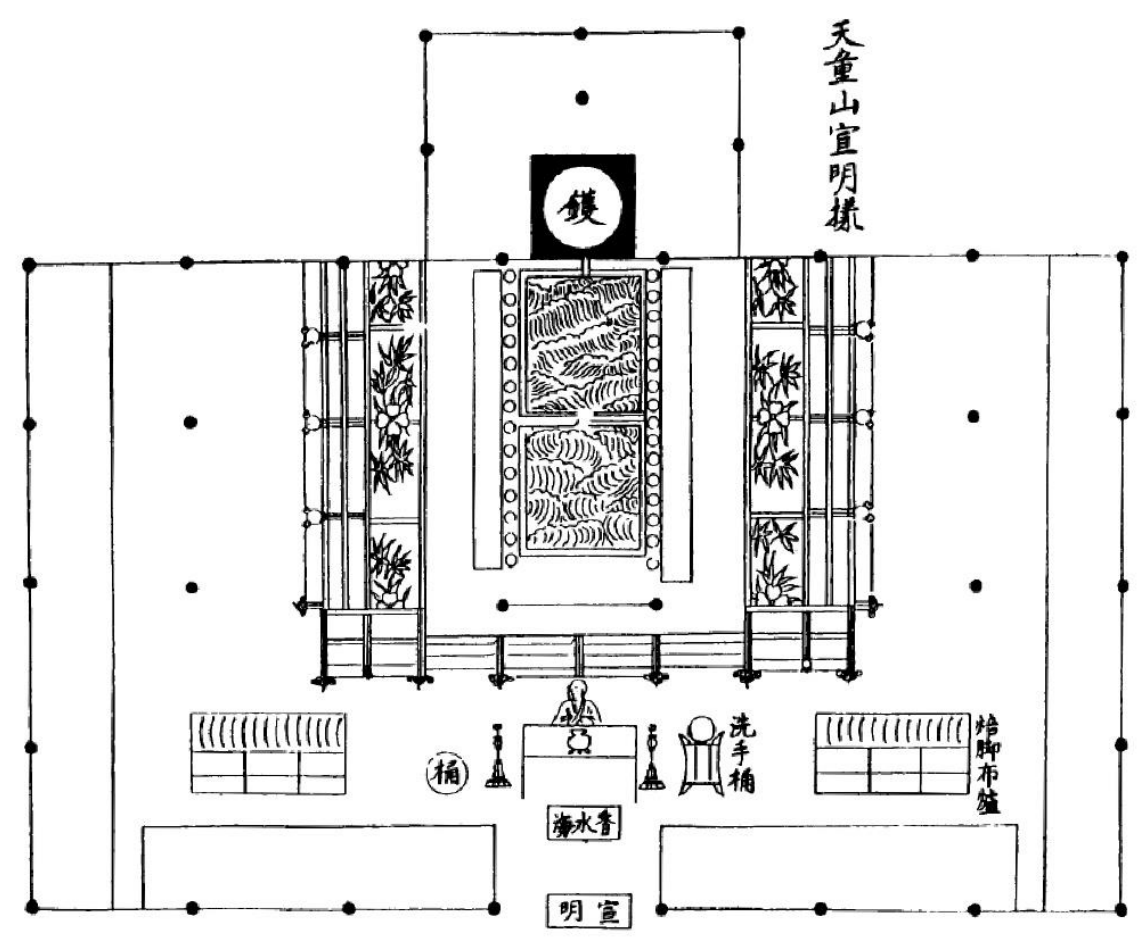

Figure 8. The bathroom of Tiantong Temple in Ningbo in "Five Mountains and Ten Temples." Source: Shiqing Zhang, The Five Mountains and Ten Temples and the Southern Song Dynasty Jiangnan Temple [M]. Nanjing: Southeast University Press, 2000: 126.

\footnotetext{
3 "The post pavilion and guest house are like bathrooms, and the doors are decorated with colored glaze." See Liu Yu's Western Ambassadors, pages 1-2.
} 
After the Ming dynasty, the Mixed Hall became more common in the literature, Lang Ying describes in detail the structure of the Mixed Hall, "The world has a Mixed Hall, as does Hangzhou. It is Wu convention to have a large brick-domed pool that will serve as a large cauldron which can deliver water through a hole in the wall. It takes only one person to work the stove, and the water will then successfully boil. This is referred to as a Mixed Hall." ${ }^{[10]}$ Wen Zhenheng from Suzhou also noted in his Chronicle of Essential Items (Zhang Wu Zhi): "A wall separates the front and back rooms, with an iron cooking pot up front with fuel-burning located in the back. Wind and cold are disallowed in private chambers. A wheel-equipped well is situated near the wall to divert water to an aperture in order to draw water out of a trench. Bath towels and other items are included." [11] The bathrooms described here were all located in the Jiangnan area. There were bathing areas in the bathroom, a brick-domed structure, an iron cooking pot in the front, and a stove in the back; other features were very similar to what is mentioned in this article.
During the Ming and Qing dynasties, the dome-roofed Mixed Hall became a major public building. There were many bathrooms inside and outside Yangzhou City. The "screw roof" bathroom in the Yangzhou Painted Boat Record (Yangzhou Hua Fang $\mathrm{Lu}$ ) is probably also a cistern-style brickdomed structure ${ }^{[12]}$. There is an old saying in Suzhou City that there were "seven towers, eight buildings, and nine steamed buns." Legend has it that "nine steamed buns" referred to the nine dome-top bathing areas in the city ${ }^{[13]}$. A public bathroom in the "Growing in the Prosperous Age" (Shengshi Zisheng Tu) artwork depicted Suzhou City during the Qing dynasty's Qianlong reign. It was located outside the Xu Gate (built in 1351) in southwestern Suzhou, on a well-trafficked road at the intersection of the Xujiang River and the moat located there, on a bustling commercial street at the head of the bridge, where one could clearly see the dome-roof building in the courtyard of the Perfume Bath Hall [Figure 9].

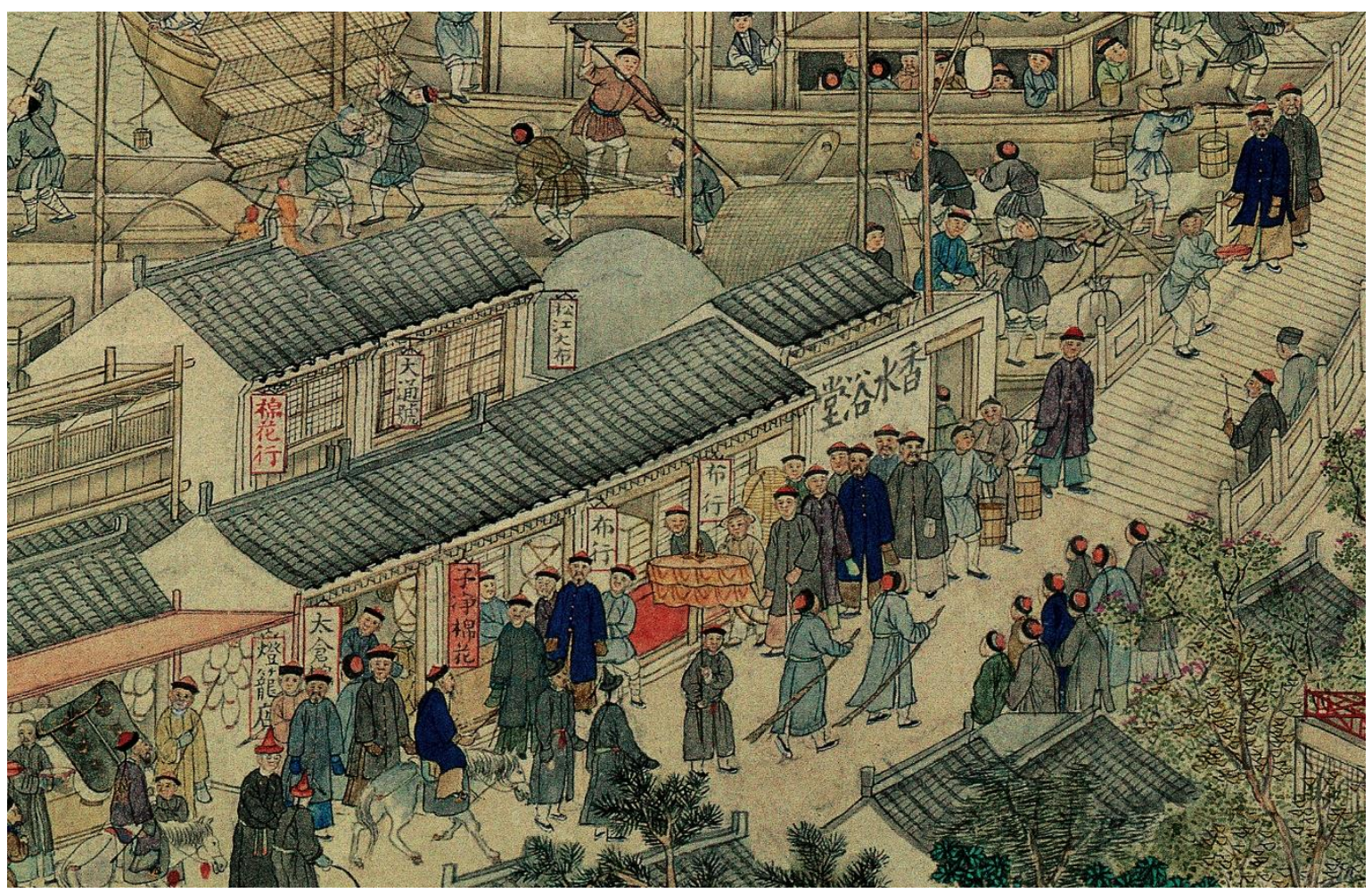

Figure 9. The Qing Dynasty Suzhou Baths in “The Prosperous Age of Breeding” (Sheng Shi Zi Sheng Tu). Source: Collection in the Liaoning Provincial Museum 
To sum up, prior to and during the Song dynasty, traditional public bath houses were mostly wooden structures. But starting in the Yuan dynasty, they became brick-vault structures, called "Mixed Halls." During the Ming and Qing dynasties, a large number of brick-domed public baths appeared and became important for leisure and entertainment.

\section{THE SOURCE OF THE SHAPE OF THE BRICK VAULT BATHROOM}

In regard to the brick-domed bathroom design sources, they began to appear in the Yuan dynasty in relation to cultural exchanges with Central and Western Asia.

According to research by Lin Mei-cun, a professor in the School of Archaeology, Arts and Sciences at Peking University, the term "Mixed Hall" may have originated from the Persian word "garm-ābag" (bathroom) or the Turco-Persian "hammān" (public bathhouse) [14]. In fact, the term "Mixed Hall" was an important early expression in the Chinese language ${ }^{4[15]}$.

Western public baths have a long history. Ancient Rome built numerous public baths with large-scale, complex functions. After being founded in West Asia in the 7th century, Islam began to spread to surrounding areas. The Quran has strict rules for bathing. Muslims pray five times a day, washing themselves prior to each prayer. The bathroom thus became an important part of Muslim life. Early Islamic architecture saw luxurious bathrooms built in mosques and palaces. The architectural form of the Islamic bathroom followed the traditions of West Asia and Persia on the one hand, and was influenced by Rome and Byzantium on the other. Built in the 8th century AD, Qasr Amra, an important relic of early Islamic architecture, was located in Jordan. The stone castle had a flat square bathroom with a dome [16]. The front part was a reception hall for leisure, with transition rooms in the middle, and a hot water bathroom was located in the back area with a central dome and half domes on both sides. The dome was similar in structure to Byzantine sail arches, and the heating and water supply used Roman bathroom techniques ${ }^{[17]}$.

With the spread of Islam, the Islamic bathroom also spread across Asia, Africa, and Europe, and gradually developed a fixed form. Today in Central Asia, West Asia, Southeastern Europe, Northern Africa, and other areas, there are still a large number of traditional Islamic public baths in mosques, bazaars, and residences ${ }^{[18-22] 5}$. The Turkish baths of the Ottoman Empire were the most famous. In Istanbul, almost every large mosque had a bathroom, and a large number of small public baths also existed [23]. The Islamic bathroom, based on Roman and Byzantine bathrooms, underwent major changes. The first was that the scale was greatly reduced, and the second was that the bathing method changed to a large degree. The Islamic bathroom canceled the Romanstyle cold-water bathroom and the method of bathing in the pool. According to the Islamic

\footnotetext{
4 "Jiao Daqingyun, the Tartar ground is extremely cold, and there are no flowers or trees. The grass is not too long, and it will be green in April, and it will be snowy in August. There is only one open mixed hall. It has four o'clock yang and warm energy. Planting a willow, the natives think that it is a different plant, and it will be watched in spring." See Zhou Mi's Guixin Miscellaneous Knowledge, page 202, Guixin Miscellaneous Knowledge Sequel, "Appreciating Willows in the North."

${ }^{5}$ Existing studies have shown that there are numerous examples of hammam remaining in eastern Europe and North Africa under the rule of the Ottoman Empire from the west to the Asian continent in the east, Turkey, Syria, Palestine, Arabia, Iran, and Uzbekistan. The time distribution is also very wide. The case of the existing bathroom in Damascus, Syria, dates from the 12th to the 20th century, and the earliest existing Ottoman bathroom in Turkey was built in the 14th century. See Kanetaki E. The still existing Ottoman Hammams in the Greek territory; Sibley M, The Pre-Ottoman Public Baths of Damascus and Their Survival into the 21st Century: An Analytical Survey; Dow M, The Islamic baths of Palestine; Sami Abd Al-Malik, Leshammamsen Arabie Centrale (J). Arabian Humanaties; Asanova G and Dow M, The Șarrāfān Baths in Bukhara (J) and Fadli F and Sibley M at the 26th Conference on the Passive and held in Canada on June 22-24, 2009 Paper at the Low Energy Architecture Quebec City conference, Hammãms of North Africa: An architectural study of sustainability concepts in a historical traditional building.
} 
regulations that the body can be cleaned with running water, the bathing method is mainly used to take water from the basin. Islamic bathrooms used neither Roman cold-water bathing nor pool bathing. While running water was used in Islamic culture, basin water was primarily used to bathe.

Judging from existing bathrooms from the 12th century, traditional bathrooms had specific characteristics. In general, the blue bathroom had a relatively fixed shape, and the composition and sequence arrangement of the rooms were roughly the same [24]. Upon entering, one would pass through a reception hall where people dressed, the warm room ${ }^{[25]}$ ${ }^{6}$, and then through the hot room with a stove room next to the hot room. The reception area was the highest, most luxurious room in the square-shaped building. The hot-water room, smaller than the reception hall, was a very important bathing space. The outer wall was generally also square-shaped. The two rooms each has a dome, and there were no windows in the walls. Lighting came mainly through circular windows in the dome. Immediately behind the hot-water bathroom was the stove room, and the floor was lower than the bathroom, with the hot water in the pot. It could be directly connected to the hot-water bathroom through pipes, and the heat generated by the stove was passed through. A flue led to the bathroom floor to maintain the indoor temperature of the hot-water bathroom. The stove room was immediately behind the hot-water bathroom, and its floor was lower than that of the hot-water room. The hot water from a cauldron was piped directly into the hot-water bathroom. For example, one could clearly see the linear arrangement from the dressing room to the hot-water bath and stove in the Ammouneh bathroom built in Damascus, Syria, in the 12th century, as well as how heating was conducted via a flue [Figure 10], creating the luxurious hot water of the Ottoman period. The bathroom composition had further complexity, with additional divisions in the interior space. Another case in point was the Yeni-Kaplica bathroom in Bursa, Turkey, built in the middle of the 16th century. The hot-water chamber was more abundant in spatial configurations. An octagonal main space was beneath the middle dome, and bathing basins were provided on all sides except near the entrance. In addition, enclosed small triangular private bathrooms were situated in the four corners ${ }^{[25]}$ [Figure 11]. The 19th-century prints depict the interior of the hot-water room of the cağaloğlu bathroom in the Osman period, by which one can see how its rich interior was used [Figure 12].

There were much in common in terms of form, space, and facilities between the Cistern Hall (Wengtang) and the Islamic bathrooms in West and Central Asia.

(1) In the form, the Islamic bathroom connected the dressing room, the fronthall bathroom, the regular bathroom and the stove room in a linear fashion, which was embodied as a linear combination of domes within the architectural space. The bathroom in the Southern Song dynasty's Five Mountains and Ten Temples (Wu Shan Shi Sha Tu), an annal of temples of that era made by Japanese monks, depicts dressing and bathing areas in a wooden building, while the cistern of the Grand Baoen Temple separated each space in a sequence of domes in the bathing area.

(2) The cistern-pool bathroom and stove room used a square-shaped brick vault, which had windows at the top of the vault for natural lighting, similar to the structure and lighting in Islamic bathroom architecture.

(3) The setting of the stove room in the cistern and the heating facilities of the underground flue were also very similar to an Islamic bathroom.

There were obvious differences between the Chinese cistern and the Islamic bathroom in the design of facilities in that the bathing traditions of each culture differed. The first

\footnotetext{
${ }^{6}$ The transitional space from the reception hall to the bathroom, where guests can slowly get used to the temperature of the hot-water room. See Vogt-Göknil U, Living architecture: Ottoman, page 173
} 
difference was the bathing method. Islamic bathrooms mainly used a basin set in the niche of the hot-water room to bathe. Hot water flowed from the stove room through a pipe in the wall and into a water basin. The center of the hot-water room was generally used for massage, and the Islamic heated stone platform hardly ever had a central bathing area for all to share together, while the Chinese cistern and Mixed Halls found in the literature on bathing patterns and architecture show that there was a central bath for everyone to bathe together, with an iron cauldron used to establish the water temperature. The method for firing the iron cauldron and setting up the bath was in line with the bathroom depicted in the Songdynasty Five Mountains and Ten Temples. The reception area and dressing room of a Chinese cistern were made of wood, with said parts of an Islamic bathroom all being brick-vault structures.

The Grand Baoen Temple cistern and the brick-vault bathrooms that became popular in China during the Yuan and Ming dynasties were most likely influenced by West and Central Asian bathrooms. The layout and technology of Chinese bathrooms were very similar to Islamic bathrooms, minus the Islamic religious nature however. The Chinese bathing method was also very different from that in Islamic bathrooms.

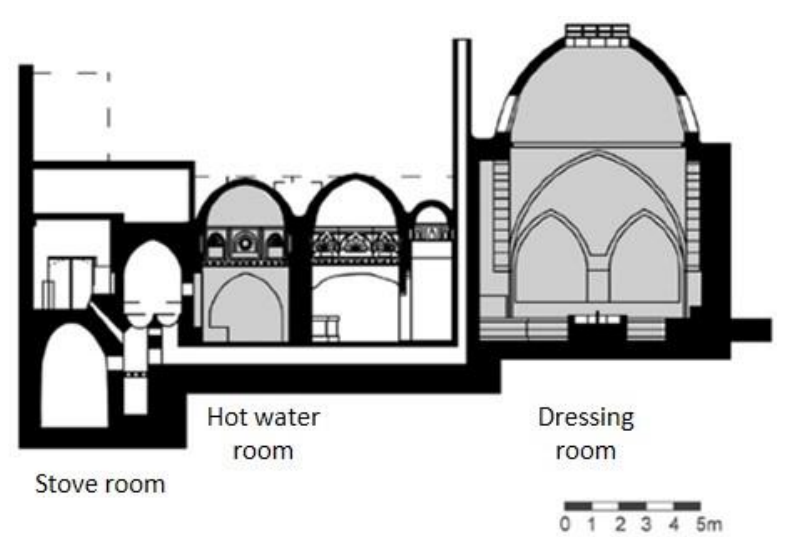

Figure 10. Section view of the Hammam Ammouneh in Damascus, Syria. Source: Sibley M., Jackson I., The architecture of Islamic public baths of North Africa and the Middle East: An analysis of their internal spatial configurations [J]. Architectural Research Quarterly, 2012(2): 168 .
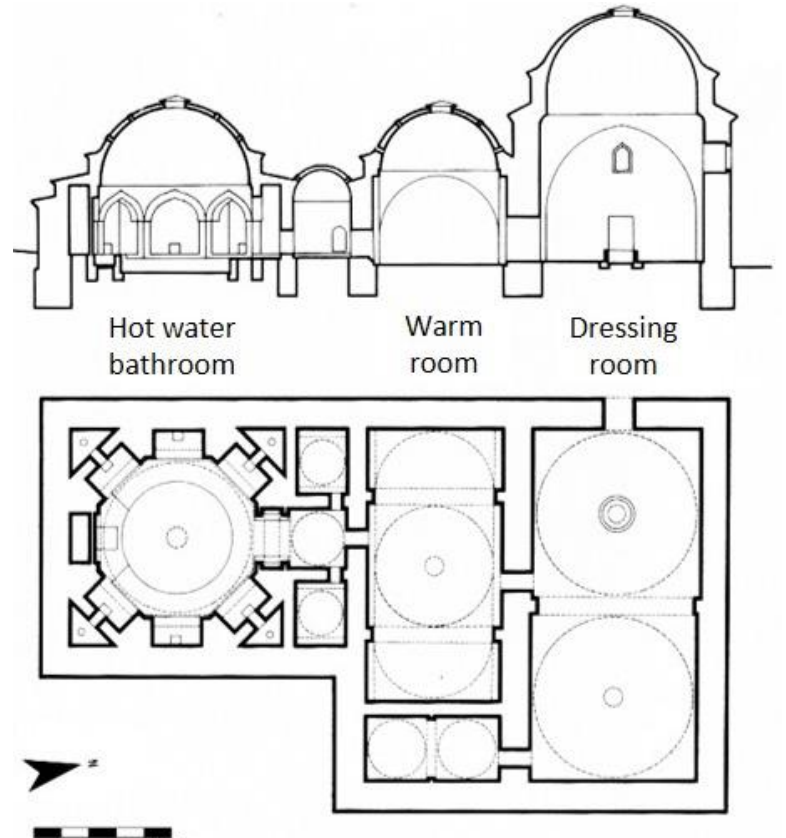

Figure 11. Plan and cross-section of the Yeni-Kaplica bathroom in Bursa, Turkey. Source: Vogt-Göknil U., Living architecture: Ottoman [M]. London: Oldbourne, 1966: 172.

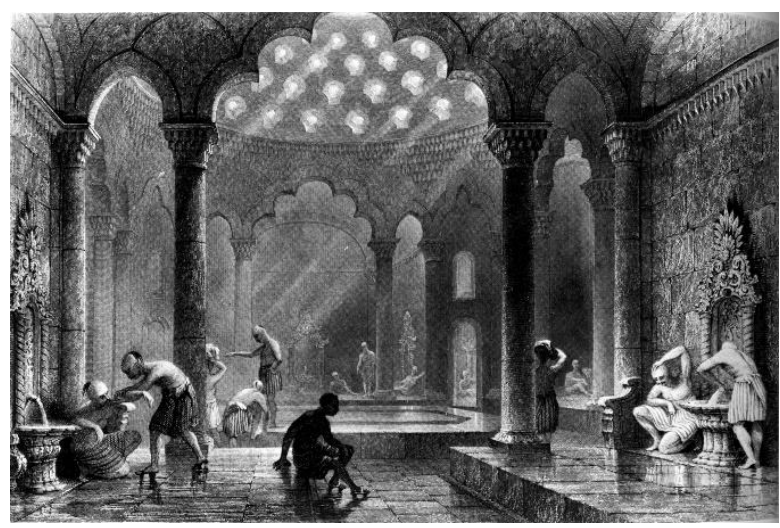

Figure 12. Cağaloğlu bathroom hot water room in the Ottoman period (19th century print). Source: Goodwin G., A History of Ottoman Architecture [M]. London: Thames \& Hudson Ltd, 1971: 378.

\section{ANOTHER BRICK-VAULT BATHROOM: YUDE HALL IN THE FORBIDDEN CITY}

Yude Hall, an annex on the northwest side of Wuying Hall in the Forbidden City of Beijing was also a brick-domed roof bathroom, used at first only by the emperor, but it was used as a Book-editing Office in the Qing dynasty. During the early Republic of China (19121949), the room was misconstrued as the "Fragrant Concubine's Bathroom." [26] 
This group of buildings consisted of a dressing area, a bathroom, a stove room and a well pavilion, with each section being kept relatively intact. The dressing room was a hard wooden building with a roll roof (juan peng ding). Its northwest corner had a Ushaped turn with a vaulted roof leading to the bathing area behind it. The stove on the north side of the back wall of the bathroom was situated east-to-west. There was a stove on both the west and east sides, and an iron cauldron boiled water that entered the bathroom via a copper pipe in the wall. The passageway, bathroom, and stove room were all made of brick. The stove room on the west side was on a lower level and had a flue passage under the floor of the bathroom that was used for heating during bathing ${ }^{[27]}$. The ground of the well pavilion outside the west wall was raised, and between the well pavilion and the stove room, a stone trough was erected to transport the water from the well to the stove room.

The bathroom, which was a square brickvault building, was changed in the Qing dynasty so that the bathroom itself no longer existed, but the structure was still well preserved. The inner side is $4.12 \mathrm{~m}$ long, and the inner surface of the upper dome is tangent to the square. The conversion between circle and square was that, first converted the square into an octagon by means of a triangular conversion layer of 14 leather bricks selected from the four corners. Next, a circular dome was placed on the octagon, passing through two additional two-brick high triangles. The walls and the inner surface of the dome were all white tiles. In the middle of the dome, a circular hole with a diameter of about $70 \mathrm{~cm}$ was opened and covered with an umbrellashaped glass skylight [Figures 13 and 14].

The construction of the Forbidden City's Yude Hall had many similarities with that of the Grand Baoen Temple's cistern. First, the two bathrooms were different from the wooden bathrooms prior to the Song dynasty. The brick-domed roof was used, and the dressing area, bathing area, stove area, and so forth were combined together but in different spaces, and the wooden structure was used in the dressing area while brick was used for the bath and stove. Second, the distinctive bathing spaces had many similarities in form, structure and construction, all of them adopting the structural form of a dome on a square plan with a similar spatial scale. In addition, the top of the two domes also had openings and glass windows that provided daylight.

The exotic style embodied in this bathroom has attracted the attention of many scholars. At present, scholars agree that it was a preserved Yuan-dynasty building in the Forbidden City of Beijing. ${ }^{7}$ However, this article presents some different opinions in this regard.

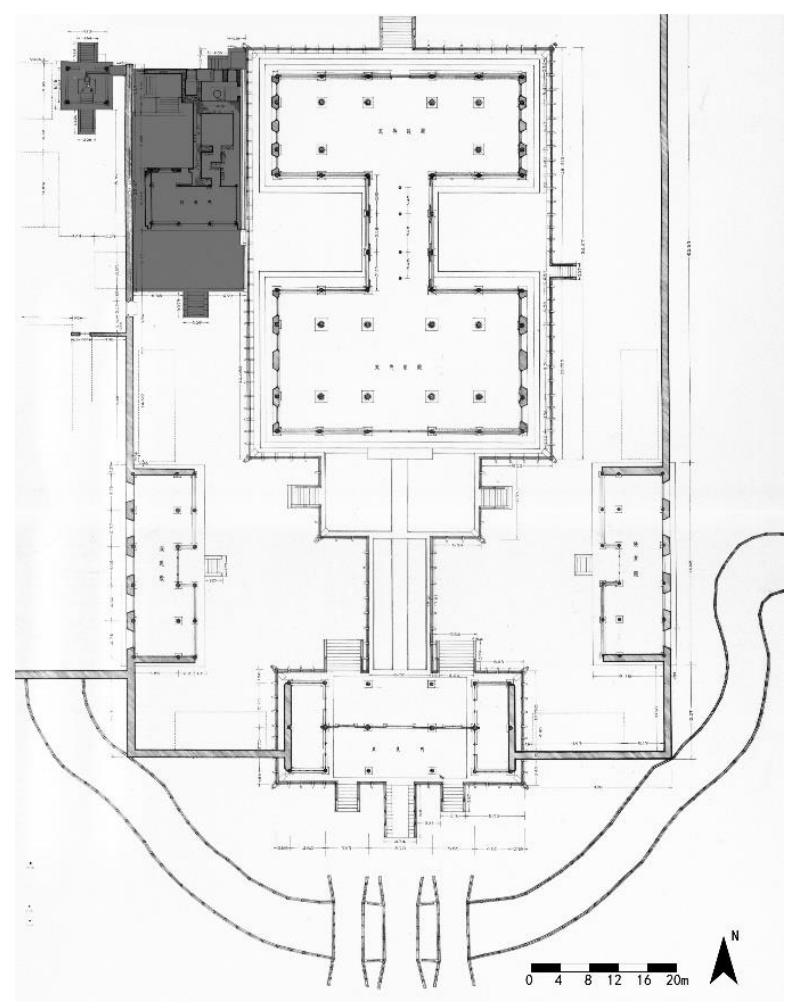

Figure 13. The position of the Forbidden City's Yude Hall in Wuying Hall. Source: Forbidden City Museum, Chinese Cultural Heritage Research Institute, Collection of measured historic buildings on the central axis of Beijing: 5 [M]. Beijing: Forbidden City Press, 2017.

\footnotetext{
${ }^{7}$ See the above cited research by Shan Shiyuan, Wang Zilin, Lin Meicun, and Changqing.
} 


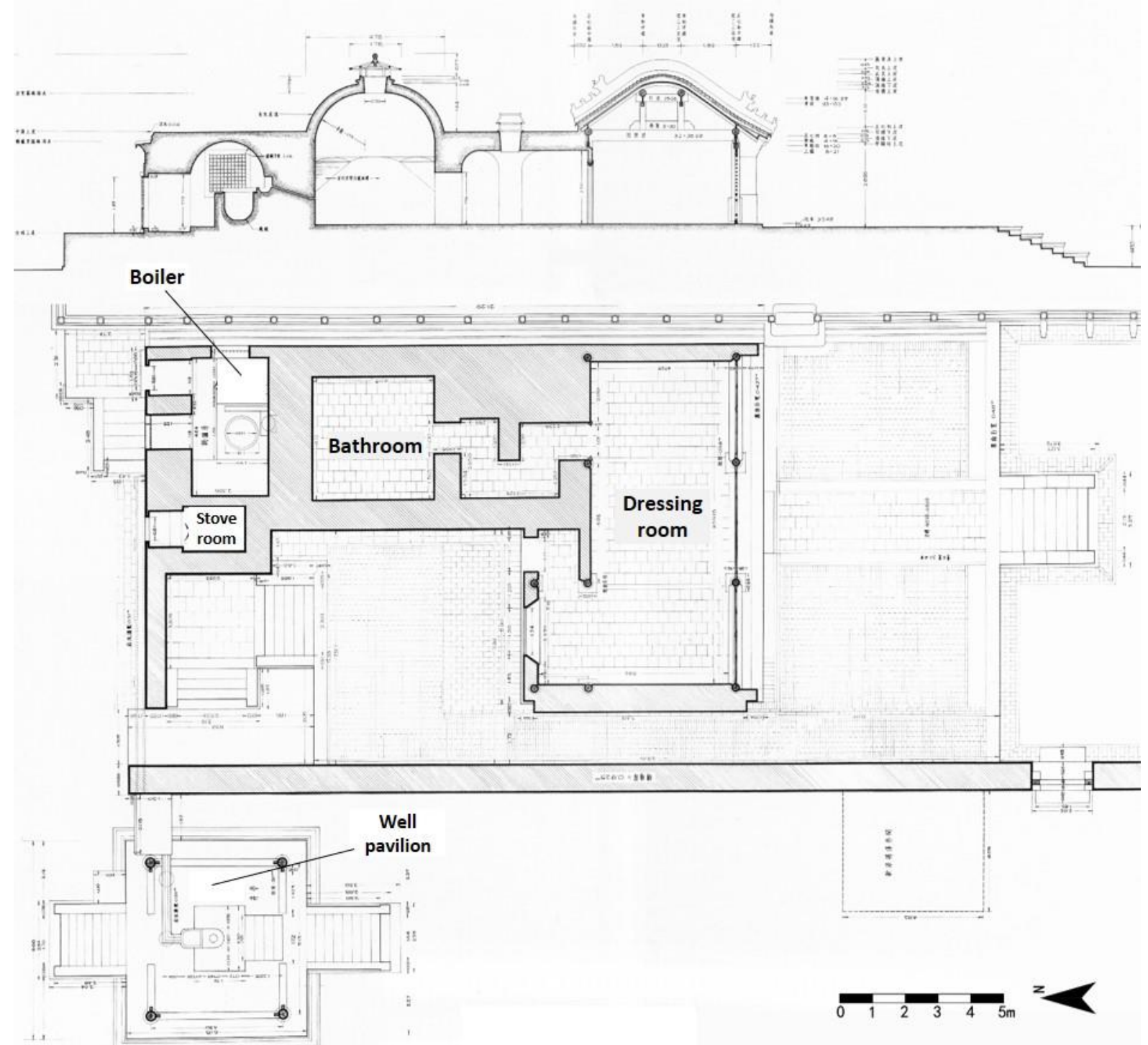

Figure 14. Plan and cross-section of the Forbidden City's Yude Hall. Source: The Palace Museum, Chinese Cultural Heritage Research Institute, Survey of historic buildings on the central axis of Beijing Atlas: Five [M]. Beijing: Forbidden City Publishing Society, 2017.

The Nanjing Palace was established as the palace system for the Ming and Qing dynasties in October of the 10th year (1377) of the Ming's Hongwu Emperor (personal name Zhu Yuanzhang). The Wenhua and Wuying Halls were in the east and west sections of the main Fengtian Hall. Wenhua Hall was "where the East Palace was for political participation," and Wuying Hall was the emperor's "dwelling place while fasting" ${ }^{[28]}$. Both buildings were ceremonially significant for the court. The Yongle Emperor (personal name Zhu Di) moved the Ming capital from Yingtian Mansion in Nanjing to Shuntian Mansion in Beijing, an event of great historical significance, the influence of which continues on into modern times. The main part of the Yude Hall building was located within the surrounding wall of the Wuying Hall courtyard. The east wall was close to the west of the base of the I-shaped Hall of Wuying Hall. There were steps on the base of the I-shaped Hall to make it easier to reach the platform in front of the Yude Hall. Wuying Hall and Yude Hall were well integrated as different buildings, sharing a very close, complex relationship wherein Yude Hall, as a probable Yuan-dynasty relic, meant that the planning, design, and construction of Wuying Hall, so important 
during the Ming, would have needed to manage a Yuan onsite bathing area, which would have been a very unreasonable notion. This article stipulates that the design of Wuying Hall and Yude Hall would have been carefully considered as a whole. The early Ming emperors fasted in Wuying Hall and bathed and dressed in Yude Hall.

Scholars believe that Yude Hall existed during the Yuan dynasty based on the following reasons:

(1) The Yude Hall bathroom was rather nontraditional in China.

(2) The white glazed tiles used in the bathroom were common in Yuandynasty palaces.

(3) The structure of the stone trough to bring water to the bathroom from the well pavilion at the back of the front hall was similar to the large Yuan inner bathrooms recorded in literature. ${ }^{8}$

This article indicates that although the Forbidden City's Yude Hall adopted the Islamic bathroom system, it was not necessarily built in the Yuan dynasty. Similar brick dome-roofed bathroom buildings were built and used during the Yuan and Ming dynasties, also affecting palace buildings and other official buildings. In the Ming dynasty, the two palaces in the north and south were equipped with Mixed Halls to manage the palace bathrooms [29] 9 . There was also a Mixed Hall in the imperial palace in Zhongdu in the southwestern sector of the Xicheng District of Beijing. Although the Forbidden City's Yude Hall adopted the Islamic bathroom system, it was not necessarily built in the Yuan dynasty ${ }^{[30]}$. In addition, white colored glaze was not unique to the court of the Yuan dynasty, having been unearthed in the Nanjing palace in the early Ming dynasty
[31] 10 . There used to be a greenhouse bathroom during the Yuan dynasty, but the content recorded in the literature does not completely correspond to Yude Hall. Therefore, Yude Hall was not necessarily built in the Yuan dynasty.

In summary, it is this article's notion that the Forbidden City's Yude Hall in Beijing and the Grand Baoen Temple's Cistern Hall (Wengtang) in Nanjing were both examples of bathrooms in the early Ming dynasty. Nevertheless, the bathing space of Yude Hall as a royal building in the Forbidden City was more spacious, and the construction process was much more elaborate than the cistern in the cities and towns of the Jiangnan region.

\section{TECHNICAL COMPARISON OF BRICK VAULT BATHROOMS}

The most notable feature in the architectural form and structure of the Mixed Hall in the Ming dynasty was the use of brick vault. The dome was an important structural form in masonry, widely used in different periods and architectural cultures throughout history. The Pantheon in Ancient Rome used a circular plan with a concrete domed roof. The Eastern Roman Empire assimilated brick vault and arch technology from Anatolia and Mesopotamia to create a Byzantine-style square-plan brick-domed roof [1]. Muslims successively conquered the Sassanid and Byzantine empires after the 7th to 8th centuries $\mathrm{AD}$. The brick-domed roof was used in Islamic architecture and appeared in Islamic buildings, such as mosques, tombs, and bathrooms.

The variability of the brick-domed structure made it very useful in a number of Islamic buildings. For example, the central dome of the iconic Byzantine Hagia Sophia

\footnotetext{
${ }^{8}$ For the first two points, see the research of Shan Shiyuan, Wang Zilin, Lin Meicun, etc., and for the second point, see Wang Zilin's "New Explanation of the Bathroom of the Forbidden City Yude Hall."

${ }^{9}$ Repairing the halls for worship: "The Nanjing Mixed Hall Secretary printed and Feng Yulin Song said that the company has three Mixed Halls, one stripping pavilion, and surrounding small houses, which are used for cooking soup every month. To provide food and support for employees, big and small, etc." See Volume 3 of Ding Bin's Ding Qinghui's Legacy.

${ }^{10}$ In 1997, a rammed earth foundation was found in the central axis area of the former part of the Ming Palace site in Nanjing, and a large number of glazed tiles were unearthed, of which yellow was the most common, followed by white, and then green. See Yang Xinhua, Nanjing Ming Palace, p.155.
} 
has a span of $33 \mathrm{~m}$, but when used in bathroom construction, the span was much smaller than that of churches and mosques. According to a study by Kader Reyhana et al. on 16 bathrooms in the Ottoman period in western Anatolia from the 15 th to 16 th centuries, 75 vaults spanned between $0.95 \mathrm{~m}$ and $12.65 \mathrm{~m}$, of which the medium span was between $3.5 \mathrm{~m}$ and $6 \mathrm{~m}^{[32]}$. Compared with this data, the vaults of the Grand Baoen Temple and Yude Hall in the Forbidden City were of the medium span commonly used in most bathroom vaults. According to the study, the larger the span, the smaller the height-span ratio of the dome. For medium-and large-span domes with a span of more than $3.5 \mathrm{~m}$, the height-span ratio is about 0.4. Judging from the value of the height-span ratio of the domed roof of the Grand Baoen Temple and Yude Hall, it also conformed to the general law of West Asian bathrooms, indicating that there was a certain technical consistency between the Chinese brick-domed bathroom and the bathroom of the Ottoman period [Table 2].

One of the key technical points of the hemispherical dome on the square plan was the conversion between square and circle. Roughly speaking, there were mainly two methods: pendentive and squinch ${ }^{[33]}$. The sail arch was a triangle with sharp corners on the bottom, and the square plan was directly converted into a circle to form the circular base of the dome. The squinch was bridged on the adjacent walls of the square plan through the squinch, forming an octagonal or circular base and providing four other fulcrums besides the tangent points of the square circle to support the circle-shaped vault. In addition to these two basic practices, there were very diverse examples in Islamic architecture, such as folded triangles and overlap overhangs. This was a highly decorative part of the domed roof structure.

Table 2. Data table of dome height-span ratio

\begin{tabular}{lllll}
\hline Project & $\begin{array}{l}\text { Cistern Hall } \\
\text { (Wengtang) bath }\end{array}$ & $\begin{array}{l}\text { Cistern Hall } \\
\text { (Wengtang) }\end{array}$ & $\begin{array}{l}\text { Yudove Hall } \\
\text { bathroom }\end{array}$ & $\begin{array}{l}\text { Medium-span Ottoman } \\
\text { bathroom in Western } \\
\text { Anatolia }\end{array}$ \\
\hline Dome span & 4.45 & 4.33 & 4.2 & $3.5 \sim 6$ \\
\hline Dome height & 1.85 & 1.71 & 1.73 & $1.10 \sim 2.81$ \\
\hline Height-span ratio & 0.42 & 0.39 & 0.41 & $0.31 \sim 0.47$ \\
\hline
\end{tabular}

Unit: meter

The vaults of square-turning and octagonal-turning domes were similarly from Central and West Asia. Compared with mosques, the domes were smaller in size and simpler in practice, and did not emphasize religious decoration. The four corners of the west dome adopted a curved triangular dome to directly transition into a circle, and the arcshaped flat surface was formed via plastering; the octagonal corner of the east dome was similar. The square corners needed to be overhung from some distance to form a round shape, and the octagonal corners formed a round shape with a much smaller distance. This can also explain why the east side dome was used even though it was a stove room. This was a complicated octagonal plan, where the technical difficulty of octagonal plan construction may have been far less than the technical difficulty of achieving a relatively large overhang in the dome. The method of assembling the Forbidden City's Yude Hall was greater than that of the Grand Baoen Temple Cistern Hall (Wengtang) because there was no plastering or whitewashing of the surface, and all the bricks were clearly visible. Therefore, the large-area arc was not used for building, but a triangle was used for the overhang. The bricks at the triangular vault corresponded to the mortar seams of the bricks on the wall oneby-one. After the octagon was formed on the 
upper part of the square, the bricks were cut into arcs in a small area at the section where the octagon turned into a circle [Table 3; Figure 15].

In addition to its use in bathrooms, hemispherical vaults were also briefly used in mosques and Islamic tombs for ground construction in China. Examples include the back kiln hall of the Phoenix Temple in Hangzhou, the back kiln hall of the Dingxian Mosque, the kiln hall of the Songjiang Mosque, and the tomb of Waqqas in Guangzhou, all of which were constructed from a square plan into a semicircular dome [1]. The Islamic vault architecture in China basically adopted a relatively simple method of overlapping triangular vaults. The overlapping parts were changed via the masonry to form water chestnut teeth decorations. In addition to the Tomb of Waqqas, all mosques added traditional Chinese roof tiles to the domes, integrating their appearance with the entire group of wooden buildings. However, after the Yuan dynasty, the brick dome structure basically disappeared from Chinese mosques and was replaced with wooden mosque complexes. The brick vaults had always existed in bathroom buildings in the Ming and Qing dynasties, and they always retained their original shapes.

Table 3. Square-Circle Conversion Method

\begin{tabular}{llll}
\hline Item & $\begin{array}{l}\text { Cistern Hall } \\
\text { (Wengtang) bathtub }\end{array}$ & Stove & Yude Hall bathroom \\
\hline Conversion method & Square to circle & Octagon to circle & $\begin{array}{l}\text { Square to octagon and then to } \\
\text { circle }\end{array}$ \\
\hline Dome method & Arc triangular overhang & Arc triangular overhang & Triangular overhang \\
\hline
\end{tabular}
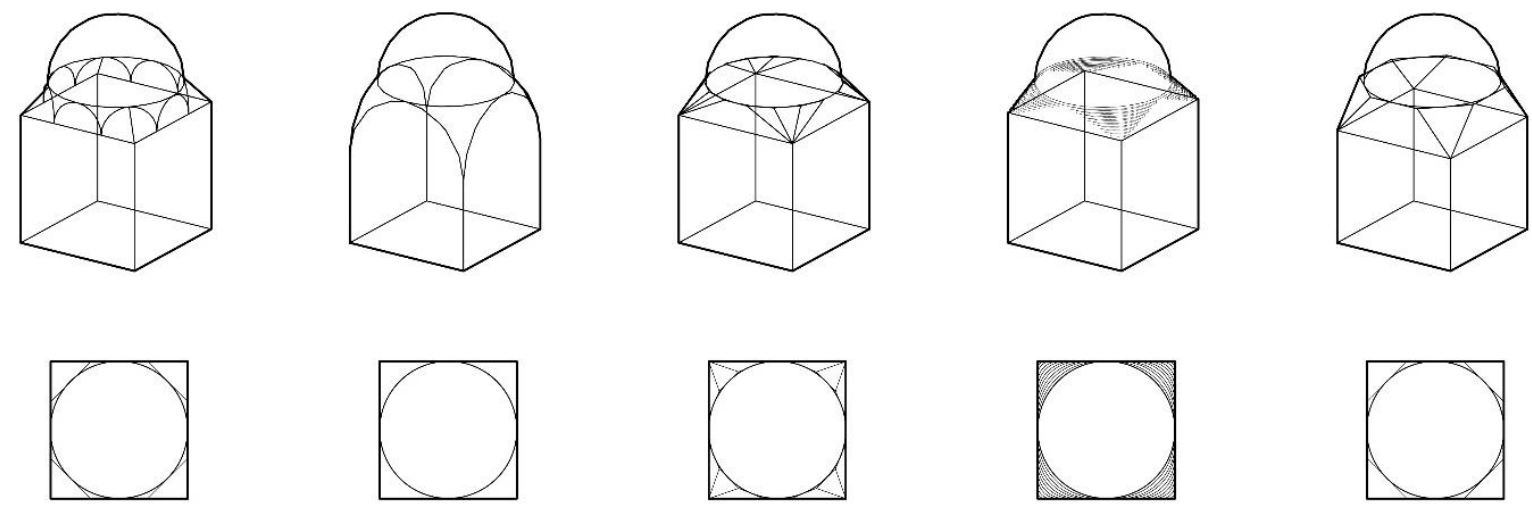

Figure 15. Schematic diagram of the dome practice. From left to right: 1 , trim arch; 2 , sail arch; 3 , folded triangle; 4, arc three angle shape [Cistern Hall (Wengtang) bath]; 5, triangle (bathroom in Yude Hall). Source: Drawing by the authors

\section{CONCLUSION}

In conclusion, this article analyzes a special type of building - the public bathroom, which was different from imposing monumental buildings, but like residential buildings, they were part of daily life. They may seem insignificant, but project important aspects of the history of architectural cultural exchanges.

Ancient Chinese architecture was not a closed system. It was influenced by different cultures during various periods in history. The Mongol Empire opened up the Eurasian continent, the movement of people brought cultural and technological exchanges, and its influence was not limited to the western provinces of China, but also directly to the Jiangnan region. This article shows that the brick-domed bathrooms that appeared in large numbers in the Yuan and Ming dynasties in the Jiangnan area of China originated from Central and West Asia; the brick-domed bathrooms that came through 
the Eurasian steppes quickly replaced the original wooden bathrooms and became the mainstream of public bathrooms. Even adopted by the Ming court, they appeared in palace complexes with ritual significance. The brick-domed bathroom did not disappear with the demise of the Yuan dynasty, but became a fixed type that lasted until the Qing dynasty. This kind of cultural exchange was not conveyed via religion, but crept into the daily life of the people, and had an impact on traditional Chinese architecture in terms of materials, forms, technology, and even aesthetics. From this perspective, the Western and Central Asian cultures that came to China through the Eurasian steppes during the Yuan dynasty may have had a far more profound impact on Chinese architecture than previously thought.

Another topic related to this is the importance of brick materials in ancient China. Used in surface construction, brick and its corresponding arch and vault technology was a product of West Asian and Mesopotamian traditions. Suitable for square plans built using brick, the circular vault is also a very symbolic architectural form. During the Yuan and Ming dynasties, with the population and technology flow in Eurasia, brick materials and brick floor building structure technology entered China, and arch and vault structures appeared there too with brick bathroom construction. The mosques in China in the Yuan dynasty retained this iconic dome structure from Central and Western Asia in the interior space of the most important kiln halls, but the appearance of the mosques still underwent a Chinese-style transformation. However, after the Ming dynasty, the interior of the architecture was quickly taken over by the wooden structure system, giving up the use of brick materials and brick vaults. However, the brick-domed bathroom that entered China during the Yuan dynasty continued into the Ming and Qing dynasties due to the practicality of using bricks with the dome space and became popular in Jiangnan. Brick arch structures had appeared in large numbers in city walls and cave buildings since the early
Ming dynasty, and they were widely popular in the Ming and Qing dynasties. They were also based on the functional considerations of materials and structures. In contrast, brick arch structures were used in only a few Buddhist temples. The choice of material and form achieves a balance between function and meaning. In functional buildings such as bathrooms, traditional underground Chinese concepts brought about the use of brick materials and exotic structural forms and proved useful on the ground. For religious buildings, significance is more important than function. This is a tradition that ancient Chinese religious buildings have always adhered to.

\section{ACKNOWLEDGMENTS}

Yumai Feng, a graduate student of Southeast University's School of Architecture, participated in the surveying and mapping work. Thanks to Lingxiao Li from Jiangsu Architectural and Garden Design Institute Co., Ltd. for conducting the onsite investigations.

\section{CONFLICT OF INTEREST}

The authors declare that they have no conflict of interest.

\section{TRANSLATOR}

Douglas Ellsworth

Email: iagodeotto@gmail.com

\section{REFERENCES}

[1] Chang Q. The civilization of the Western Regions and the changes of Chinese architecture. 1992, Hunan Education Publishing House, Changsha.

[2] Zheng Z. Uncover the mysterious history of Juen Spring in the cistern of the Ming Dynasty [J]. Zheng He Research, 2009, 2009(3): 44-45, 51.

[3] Ge Y. Jinling Pure Land Chronicles. 2006, Guangling Publishing House, Yangzhou.

[4] Wu M. Suspicion of Brahma Temple. 2006, Guangling Publishing House, Yangzhou. 
[5] Yang Z. Orchid soup and perfume [J]. Forbidden City, 2011, 2011(4): 92-98.

[6] Zhang S. The Five Mountains and Ten Temples and the Southern Song Dynasty Jiangnan Temple. 2000, Southeast University Press, Nanjing.

[7] Provincial Administration of Cultural Relics. Tang Huaqing Palace. 1998, Wenwu Press, Beijing.

[8] Huai H. The imperial repair Baizhang clear rules. 2000, Thread-Binding Books Publishing House, Beijing.

[9] Liu Y. Western Ambassador. 1985, Zhong Hua Book Company, Beijing.

[10] Lang Y. Seven revision drafts. 2001, Shanghai Bookstore Publishing House, Shanghai.

[11] Wen Z. Zhang Wu Zhi. 1936, The Commercial Press, Beijing.

[12] Li D. Records of Yangzhou Painting Boats. 1960, Zhong Hua Book Company, Beijing.

[13] Cai G. The history of Gusu Huntang [J]. Suzhou Magazine, 2003, 2003(5): 40-41.

[14] Lin M. The baptism of Persian civilization - The fourth part of Iran investigation in 2012 [J]. Forbidden City, 2012, 2012(9): 16-27.

[15] Zhou M. Guixin miscellaneous historical notes. 1988, Zhong Hua Book Company, Beijing.

[16] Wang R. History of world architecture: Islamic Volume 1. 2014, China Architecture \& Building Press, Beijing.

[17] Ettinghausen R, Grabar O, JenkinsMadina M. Islamic art and architecture 650-1250. 2001, Yale University Press, New Haven and London.

[18] Kanetaki E. The still existing Ottoman Hammams in the Greek territory [J]. METU JFA, 2004, 2004(1-2): 81-110.

[19] Sibley M. The pre-Ottoman public baths of Damascus and their survival into the 21st century: An analytical survey [J]. Journal of Architectural and Planning Research, 2007, 2007(4): 271-288.

[20] Dow M. The Islamic baths of Palestine. 1996, Oxford University Press, Oxford.
[21] Sami Abd Al-Malik. Les hammams en Arabie centrale $[\mathrm{J}]$. Arabian Humanaities. 2012, 2012(17). http://journals.openedition.org/cy/1801

[22] Asanova G, Dow M. The Șarrāfān Baths in Bukhara [J]. Iran, 2001, 2001(1): 187205.

[23] Boyar E, Fleet K. A social history of Ottoman Istanbul. 2010, Cambridge University Press, New York.

[24] Sibley M, Jackson I. The architecture of Islamic public baths of North Africa and the Middle East: An analysis of their internal spatial configurations [J]. Architectural Research Quarterly, 2012, 2012(2): 155-170.

[25] Vogt-Göknil U. Living architecture: Ottoman. 1966, Oldbourne, London.

[26] Shan S. Investigation of Yude Hall in the Forbidden City's Wuying Hall [J]. Palace Museum Journal, 1985, 1985(3): 45-48, 68.

[27] Wang Z. A new interpretation of the bathroom of the Forbidden City Yude Hall [J]. Forbidden City, 2011, 2011(11): 22-27.

[28] Hu G. Records of Ming Taizu. 1962, Institute of History and Philology, Academia Sinica, Taipei.

[29] Ding B. The collected works of Ding Qinghui. The Compilation Committee of the Si Ku Jin Hui Shu Congkan. Si Ku Jin Hui Shu Congkan: Collection 44. 1997, Beijing Publishing House, Beijing.

[30] Liu Y. Chenghua Zhongdu Zhi. Shanghai Bookstore. The continuation of the selected publications of Ming Dynasty local chronicles in the Tianyi Pavilion collection: 33. 1990, Shanghai Bookstore, Shanghai.

[31] Yang X. Ming Palace of Nanjing. 2009, Nanjing Publishing House, Nanjing.

[32] Reyhan K, Başakipekoğlu, Böke H. Construction techniques of domes in some Ottoman baths [J]. Journal of Cultural Heritage, 2013, 2013(3): 35-40.

[33] Petersen A. Dictionary of Islamic architecture. 1996, Routledge, London. 